\title{
Drenaj Alan-Oran Metodu Kullanılarak Nehir Akım Verilerinin Yanlılık Düzeltmesi ile Doğruluğunun İncelenmesi
}

\author{
Serin Değerli ${ }^{1}$, Evren Turhan ${ }^{2 *}$ \\ ${ }^{\mathbf{1}}$ Adana Alparslan Türkeş Bilim ve Teknoloji Üniversitesi, Mühendislik Fakültesi, İnşaat Mühendisliği Bölümü, Adana, Türkiye, (ORCID: 0000-0003-0208-9152), \\ sdegerli@atu.edu.tr \\ 2* Adana Alparslan Türkeş Bilim ve Teknoloji Üniversitesi, Mühendislik Fakültesi, İnşaat Mühendisliği Bölümü, Adana, Türkiye, (ORCID: 0000-0002-0742-4848), \\ eturhan@atu.edu.tr
}

(2nd International Conference on Applied Engineering and Natural Sciences ICAENS 2022, March 10-13, 2022)

(DOI: 10.31590/ejosat.1075180)

ATIF/REFERENCE: Değerli, S. \& Turhan, E. (2022). Drenaj Alan-Oran Metodu Kullanılarak Nehir Akım Verilerinin Yanlılık Düzeltmesi ile Doğruluğunun İncelenmesi. Avrupa Bilim ve Teknoloji Dergisi, (24), 100-104.

\begin{abstract}
Öz
Su kaynaklarının planlanma süreçleri içerisinde havza modelleme çalışmalarında kullanılabilecek meteorolojik ve hidrolojik parametrelerin detaylı bir şekilde araştırılması oldukça önemlidir. Özellikle baraj, gölet, köprü, menfez gibi su yapıları tasarlanırken, uzun periyotları kapsayan verilerin eksiksiz olması, noksan olması halinde ise uygun yöntemlerle tahmin edilebilmesi gerekmektedir. Ancak birçok sebepten ötürü bu verilerin tam olamadığı görülebilmektedir. Eğer akım ölçümü su yapısının planlandığı yerde yapılamıyor ise mevcut verilerin istenilen bölgeye doğru bir şekilde taşınabilmesi gerekebilir. Bu kapsamda Drenaj Alan-Oran (DAR) yöntemi, bahsedilen ölçümlerin taşınmasında kullanılan metotlardan biridir. Bu çalışmada, Doğu Akdeniz Havzası'ndaki Elektrik İşleri Etüt İdaresi (EİĖ̇) tarafından işletilmiş olan 1712, 1717 ve 1721 nolu Akım Gözlem İstasyonlarının (AGİ) gözlemlenmiş akım verilerinden faydalanılmıştır. 1987-2011 yılları arası aylık akım verileri değerlendirilmiş olup, 1712 nolu istasyonun verileri, birbirlerinden farklı uzaklıktaki 1717 ve 1721 nolu istasyonların bulunduğu konuma DAR metodu ile taşınmıştır. Elde edilen değerler orijinal (ham) veriler ile karşılaştırılarak yöntemin doğruluğu sınanmıştır. Ayrıca Yanlılık Düzeltmesi (Bias Correction) uygulandığında taşınan verilerin gözlenen veriler ile ne oranda yakınsak olduğu irdelenmiştir. Çalışma sonucunda Yanlılık Düzeltmesi ile ortaya konan hesapların düzeltme yapılmadan taşınan değerlere göre orijinal veriler açısından daha yakın değerler verdiği görülmüştür. Dolayısı ile su kaynaklarının doğru ve etkili yönetimi aşamaları düşünüldüğünde eksik akımların tamamlanması çalışmalarında havza genelindeki eşdeğer gözlem istasyonları verilerinin drenaj alanlarına göre düzeltmeleri yapılarak taşınmasının tasarım ve maliyet hesaplamalarına olumlu anlamda etki yapabileceği öngörülmektedir.
\end{abstract}

Anahtar Kelimeler: Su Kaynakları Yönetimi, Akım Doğruluk Analizi, Drenaj Alan-Oran Metodu, Yanlılık Düzeltmesi, Doğu Akdeniz Havzası.

\section{Investigation of Streamflow Data Accuracy with Bias Correction Using Drainage Area-Ratio Method}

\begin{abstract}
It is very important to analyze in detail the meteorological and hydrological parameters that can be used in drainage basin modeling studies within the planning processes of water resources. Especially when designing hydraulic structures such as dams, ponds, bridges and culverts, long-term data should be complete and in case of shortcoming, it should be estimated by appropriate methods. However, it can be seen that these data are not complete for many reasons. If the flow measurement cannot be made where the water structure construction is planned, it may be necessary to transfer or transport the available data to determined region appropriately. In this context, Drainage Area-Ratio (DAR) method is one of the methods used to transport the relevant observation streamflow values. In
\end{abstract}

* Sorumlu Yazar: eturhan@atu.edu.tr 
this study, the observed streamflow data of Stream Gauge Stations (SGS) numbered 1712, 1717 and 1721 operated by the Electrical Works Survey Administration (knownly as EIEI) in the Eastern Mediterranean Basin, were used. The monthly flow data between 1987 and 2011 were utilized, and the data of the SGS-1712 were transferred to the location of the SGSs 1717 and 1721 , which are at different distances from each other, with the DAR method. The accuracy of this method was tested by comparing the obtained values with the original (raw) data. In addition, when Bias Correction (BC) is applied, the extent to which the transferred data converge with the observed data was examined. As a result of the study, it has been seen that the results using the BC give closer values than the values transferred without the correction in terms of the original data. Therefore, considering the stages of accurate and effective water resources management, it is predicted that transporting the equivalent gauge stations streamflow data throughout the basin by correcting them according to the drainage areas in the completion of the missing flows, can be a positive effect on the design and cost calculations.

Keywords: Water Resources Management, Streamflow Accuracy Analysis, Drainage Area- Ratio Method, Bias Correction, Eastern Mediterranean Basin.

\section{Giriş}

Su, yeryüzündeki tüm canlılar açısından hayati bir öneme sahiptir. Suyun bu önemi geçmişten günümüze kadar su kaynaklarının daha verimli kullanılmasını, kontrolünü, her türlü doğal afetlerden korunmayı temel hedef haline getirmiştir. İçme suyu ve tarımsal amaçlı kullanılan tatlı su hidroelektrik, suyu depolama, su getirme ve su ulaşımı gibi ihtiyaçları da karşılayabilmektedir. Bu doğrultuda su kaynaklarının doğru bir şekilde tasarımının yapılabilmesi ve işletilmesi için akım verilerinin hidrolojik olarak incelenmesi oldukça önemli olmaktadır [1-3]. Elde edilen bu verilerin eksiksiz bir şekilde olması planlama ve tasarım aşamaları açısından temel kriterlerdendir. Ancak havzalarda çoğu akarsu ve nehirlerin her noktası için bu ölçümlerin yapılabilmesi oldukça zor ve maliyetli olabilmektedir.

Bir havzadaki eksik olan ya da bazı sebeplerden (iklim koşulları, ulaşım zorlukları, ölçüm cihazındaki sorunlar,...vb.) dolayı ölçülemeyen veriler olabilmektedir. Bu sorunları ortadan kaldırabilmek amacıyla birçok çalışma yapılmış ve metotlar geliştirilmeye çalışılmıştır. Bu çalışmada da değinildiği üzere literatürde eksik verilerin tamamlanması için Drenaj Alan-Oran (DAR) metodunun yardımıyla eksik verilerin tamamlanmasına yönelik uygulamalar göze çarpmaktadır [1-2, 4, 5].

Bu yöntem havzada var olan Akım Gözlem İstasyonu (AGİ) verilerinin farklı bir AGI'ye alanlarının oranı şeklinde aktarılmasını ifade etmektedir. Eksik verilerin tamamlanmasında ya da ölçülen verilerin doğruluğunun analizinde DAR metodunun birçok alanda kullanılabildiği belirtilmektedir [6-8].

Çalışma kapsamında Türkiye'nin önemli drenaj alanlarına sahip havzalarından biri olan Doğu Akdeniz Havzası içerisinde yer alan Elektrik İşleri Etüt İdaresi (EİEİ) tarafından işletilmiş olan 1712, 1717 ve 1721 nolu Akım Gözlem İstasyonlarının (AGI) 1987-2011 yılları arası 25 yıllık akım verileri doğruluk analizinin yapılması amacı ile tercih edilmiştir.

Söz konusu 1712 nolu istasyon verilerinin, birbirlerinden farklı uzaklıktaki 1717 ve 1721 nolu istasyonların bulunduğu konuma Drenaj Alan-Oran (DAR) Metoduyla taşınmıştır. Bu orijinal (ham) ve taşınan veriler arasındaki hata oranı yani sapma miktarları ve yaklaşıklık durumları incelenmiştir. Akım gözleminin mümkün olamadığı alanlarda bu tip yöntemlerin kullanımı neticesinde su yapılarının planlanması ve tasarımı aşamasında önemli katkılarının olabileceği öngörülmektedir.

\section{Materyal ve Metot}

\section{1. Çalışma Alanı}

Devlet Su İşleri (DSİ) tarafından Türkiye'de toplam 25 adet ana havza belirlenmiştir. Doğu Akdeniz Havzası bu havzalar içerisinde 17 nolu havza olarak ifade edilmektedir. Havza Türkiye'nin güneyinde $36^{\circ} 00^{\prime}-37^{\circ} 28^{\prime}$ Kuzey Enlemleri ve $32^{\circ} 06^{\prime}-35^{\circ} 09^{\prime}$ Doğu Boylamları arasında yer almaktadır. Doğu Akdeniz Havzası $21.676 \mathrm{~km}^{2}$ drenaj alanına sahip olup Türkiye nüfusunun yaklaşık \%2,4'ünü barındırmaktadır. Havzadaki yıllık ortalama yağış $745 \mathrm{~mm}$ olup, havzadaki yıllık su potansiyeli $11,07 \mathrm{~km}^{3}$ olarak belirlenmiştir. Havza yaklaşık 2.180.704 hektar (ha) ile ülke yüzölçümünün yaklaşık \%2,8'ini oluşturmaktadır [9].

\subsubsection{Akım Gözlem İstasyonu Bilgileri}

Bu çalışmada Doğu Akdeniz Havzası'nın Şekil 1'de görülen alt havzaları içerisinde yer alan 1712, 1717 ve 1721 nolu Akım Gözlem İstasyonu (AGI) aylık ortalama akım verilerinden faydalanılmıştır.

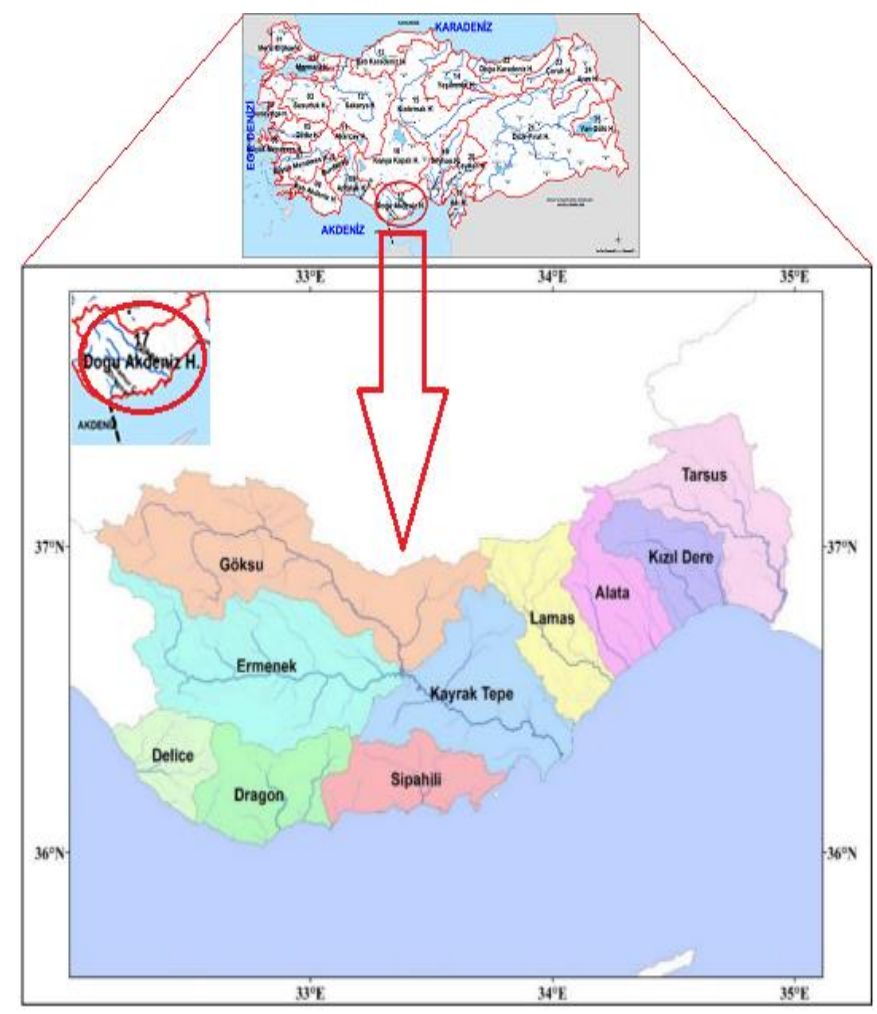

Şekil 1. Doğu Akdeniz Havzası genel konumu [11] 
1712 nolu AGİ Karaman ili merkez ilçesinin $42 \mathrm{~km}$ güneyinde Bucakkışla Bucağında Göksu Nehri üzerinde bulunmaktadır. 1717 nolu AGİ Mersin ili Silifke ilçesi Kırobası Bucağına bağlı Kızılgeçit Köyündeki Lamas Çayı üzerindeki köprüdedir. Mersin'e bağlı Anamur ilçesinin kuzeyinde Ermenek yolu üzerindeki Ala Köprüdedir. İstasyon bilgileri Tablo 1'de verilmektedir. Ayrıca Şekil 2'de bahsi geçen AGİ'lerin havzadaki konumları gösterilmektedir [10].

\subsubsection{Alan-Oran Metodu}

DAR metodu, aynı havzada bulunan su kaynaklarının üzerinde kurulmuş olan bir AGİ tarafından ölçülen verilerin başka bir noktada ya da bir yerde kurulu olan AGİ'nin mansabındaki bir noktaya taşınmasını ifade etmektedir [1-2]. Bu metodun kullanılabilmesi için havzaya ait AGI'lerden elde edilen $\phi$ ve K katsayıları mutlaka belirlenmelidir. Genel olarak bu metotta $\mathrm{Q}=\mathrm{K}$.A $\phi$ formülü kullanılmaktadır. Formülde $\mathrm{Q} \mathrm{m}^{3} / \mathrm{s}$ cinsinden olup günlük, aylık ya da yıllık olarak akış miktarını ifade etmektedir, $\mathrm{A} \mathrm{km}^{2}$ cinsinden olup seçilen noktaya kadar olan yağış alanını ifade etmektedir. $\phi$ üstel ve $\mathrm{K}$ ise düzeltme katsayılarıdır. Örneğin akarsu üzerinde 1 noktasında bir AGİ olduğu düşünülürse, bu AGI'nin alanı, $A_{1}$ ve ölçülen debisi Q' $\operatorname{dir}[4]$.

Tablo 1. Akım gözlem istasyonu bilgileri [10]

\begin{tabular}{c|c|c|c}
\hline İstasyon No & Enlem (K) & Boylam (D) & $\begin{array}{c}\text { Drenaj } \\
\text { Alanı (km²) }\end{array}$ \\
\hline 1712 & $36^{\circ} 57^{\prime} 03^{\prime}$, & $33^{\circ} 02^{\prime} 11^{\prime}$, & 2689,2 \\
\hline 1717 & $36^{\circ} 39^{\prime} 34^{\prime \prime}$ & $34^{\circ} 00^{\prime} 02^{\prime}$, & 1005,2 \\
\hline 1721 & $36^{\circ} 10^{\prime} 32^{\prime}$, & $32^{\circ} 23^{\prime} 44^{\prime}$, & 313,2 \\
\hline 1712
\end{tabular}

Şekil 2. 1712, 1717 ve 1721 AGI'lerin harita üzerindeki konumlarl [10]

Verilerin taşınacağı 2 noktasının havza drenaj alanı $A_{2}$ ve debisi $\mathrm{Q}_{2}$ olarak değerlendirilirse, Denklem 1 ve 2 aşağıdaki gibi yazılabilir [2]:

$$
\begin{aligned}
& Q_{1}=K_{1}\left(\frac{A_{1}}{A_{2}}\right)^{\phi} \\
& Q_{2}=K_{2}\left(\frac{A_{2}}{A_{1}}\right)^{\phi} Q_{1}
\end{aligned}
$$

Alan-Oran metodunun genel formülünü kullanabilmek için Yanlılık Düzeltmesi (Bias Correction) uygulanmadan yapılan işlemlerde aynı havza içerisinde bulunan akarsuların benzer özellik taşıyabileceğinden dolayı formülde bulunan $\phi$ üstel ve $K$ düzeltme katsayılarının 1 değerini aldığı görülebilmektedir $(\phi=1$, $K=1$ ) [4]. Düzeltme sonucunda denklemde bulunan $\phi$ üstel sayıları hesaplanarak, elde edilen değerlerin aritmetik ortalaması alınıp tek bir değere ulaşılmaktadır. Denklem 3 ve 4 'te kullanılan formüller görülebilmektedir [8]:

(3)

$$
\phi_{i 1}=\frac{\log \left(Q_{1 i} / Q_{2 i}\right)}{\log \left(A_{1} / A_{2}\right)}
$$

$$
\bar{\phi}=\frac{1}{n} \sum_{i=1}^{n} \phi_{i}
$$

Burada, $n$ örnek sayısını; $i$ ise i. sıradaki akım değerlerini ve o sıra için $\phi$ 'yi ifade etmektedir. Hataları en aza indirebilmek amacı ile formülde kullanılan diğer bir katsayısı olan $K^{\prime}$ 'nın iki AGİ arasındaki değerini bulmak için aşağıda belirtilen denklem yardımı ile hesaplamaları yapılır (Denklem 5 ve 6) [8]:

$$
\begin{aligned}
12^{K_{i}} & =\frac{Q_{1 i}}{Q_{2 i}\left(\frac{A_{1}}{A_{2}}\right)^{\bar{\phi}}} \\
21^{K_{i}} & =\frac{Q_{2 i}}{Q_{1 i}\left(\frac{A_{2}}{A_{1}}\right)^{\bar{\phi}}}
\end{aligned}
$$

Yanlılık Düzeltmesi ile DAR metodunun hesaplanabilmesi için tek bir $K$ katsayısına ihtiyaç vardır. Bu doğrultuda elde edilen bu değerleri tek bir sayıya dönüştürmek ve genelleştirilmiş formülde kullanılabilmesi amacıyla Denklem 7 ve 8 uygulanmaktadir:

$$
\begin{aligned}
& \mathrm{K}=\frac{1}{2 n} \sum_{i=1}^{n} 12^{K_{i}}+21^{K_{i}} \\
& \bar{Q}_{1}=Q_{2} K\left(\frac{A_{1}}{A_{2}}\right)^{\bar{\phi}}
\end{aligned}
$$

$\mathrm{Bu}$ denklemlerin gerçekleştirilmesi ile birlikte havzada iki nokta arasındaki DAR metodu uygulanabilir seviyeye gelebilmektedir.

\section{Araştırma Sonuçları ve Tartışma}

1712, 1717 ve 1721 nolu AGÍ'lerin 1987-2011 y1lları aras ortalama aylık veriler kullanılarak akım verilerinin doğruluğu analiz edilmiştir. Yanlılık Düzeltmesinin kullanılmadığ 1 halde 1712 nolu istasyon verilerinin 1717'ye taşındığ durumda elde edilen grafik Şekil 3'te çizilmiştir.

Şekil 3'te görülebileceği üzere taşınan akım değerlerinin ham veya orijinal değerlerle arasında özellikle 1712 AGÍden 1721 AGI'ye doğru büyük sapmalar, önemli farkların olduğu gözlenmiştir. Buradan hareketle DAR metodunun uygulanabilir bir düzeyde olduğu fakat doğruluk analizi için gerçek sonuçlara göre hata oranının yüksek olduğu söylenebilir.

Sonuçların yaklaşıklığını arttırabilmek için Yanlılık Düzeltmesi uygulanmış, elde edilen sonuçlar üzerine tekrar değerlendirmeler yapılmıştır. Düzeltme taşınan değerlerin $\phi$ 
üstel ve K katsayıları için sabit bir değer kullanılmayıp, ortalama bir değer elde edildikten sonra denklemlere dahil edilmesi şeklinde ele alınmıştır. Katsayı değerleri yapılan çalışmalar sonucunda Tablo 2'de verildiği gibi bulunmuştur. İlaveten Şekil 4'te Yanlılık Düzeltmesi sonucu ham ve taşınan verilerin grafikleri görülebilmektedir.

\section{(a) 1712 AGI'den 1717 AGI'ye Taşınan Veriler}

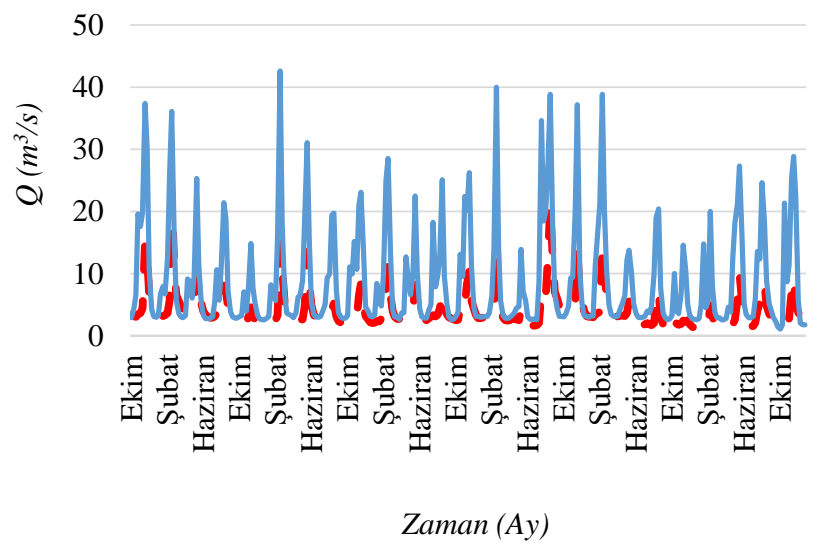

- HAM VERI TAŞINMIŞ VERI

(b) $1712 A G \dot{I}^{\prime}$ den 1721 AGI'ye Taşınan Veriler

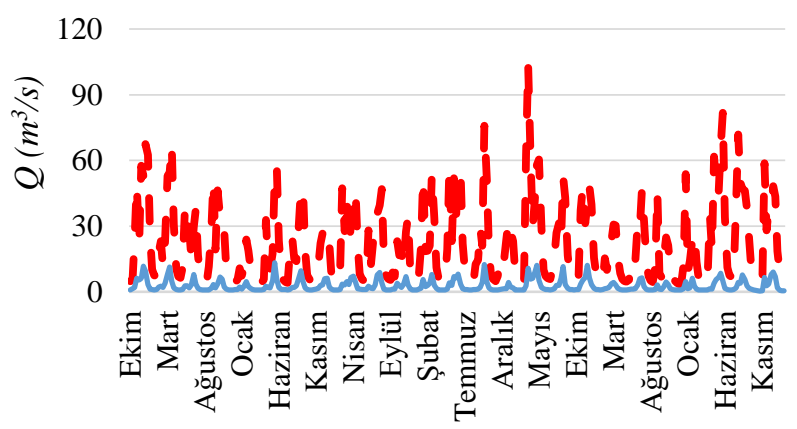

$\operatorname{Zaman}(A y)$

- - HAM VERI

\section{TAŞINMIŞ VERI}

Şekil 3. (a) 1712 AGI'den 1717 AGI'ye taşınan verilerin,

(b) 1712 'den 1721 AGI'ye taşınan verilerin grafikleri

Tablo 2. Yanlılık düzeltmesi ile ortalama $\phi$ üstel ve K düzeltme katsaylları

\begin{tabular}{c|c|c}
\hline İstasyon No & 申ort & $\mathbf{K}_{\text {ort }}$ \\
\hline $1712-1717$ & 1,6354722 & 1,155194 \\
\hline $1712-1721$ & 0,048722 & 1,088752 \\
\hline
\end{tabular}

(a) 1712 AGI'den 1717 AGI'ye Taşınan Verilerin Düzeltilmesi

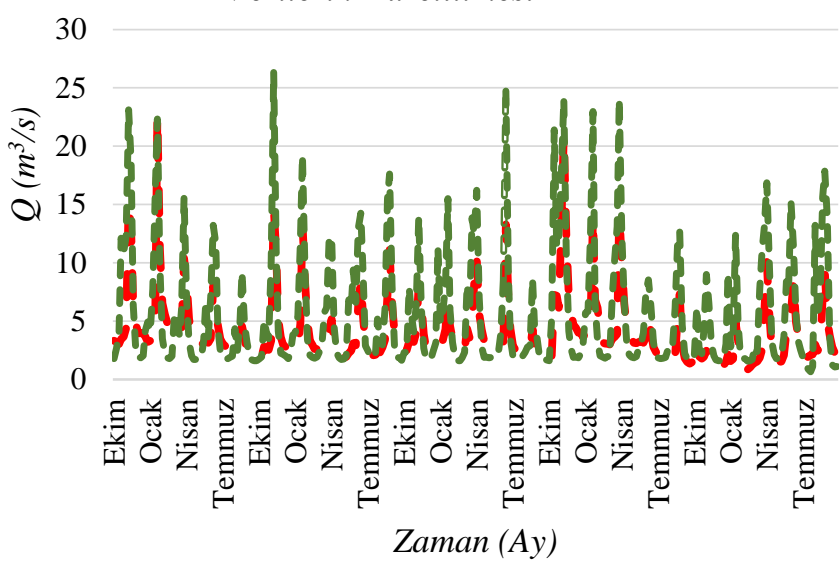

— HAM VERI ——DÜZELTILMIŞ VERI

(b) 1712 AGI'den 1721 AGI'ye Taşınan Verilerin Düzeltilmesi

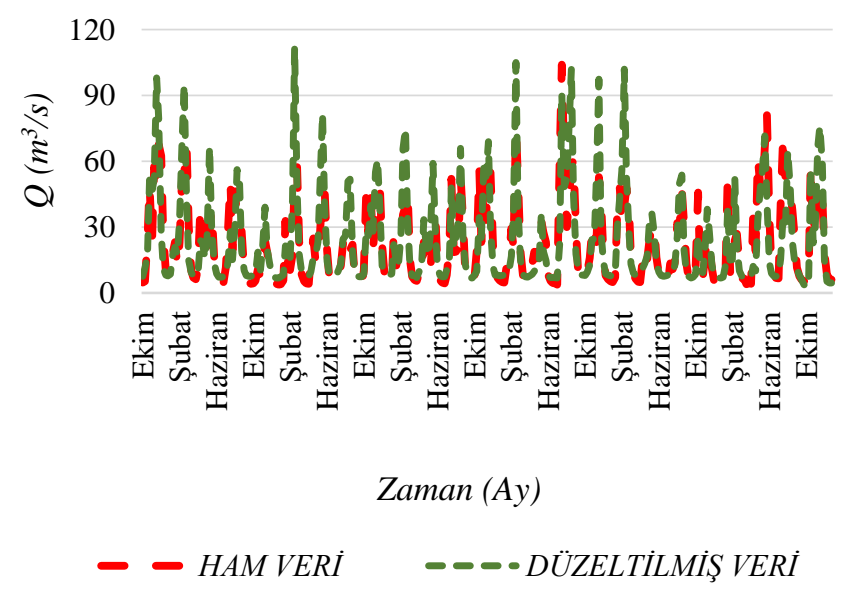

Şekil 4. (a) 1712 AGI'den 1717 AGI'ye taşınan verilerin düzeltilmesi, (b) 1712'den 1721 AGI'ye taşınan verilerin düzeltilmesi grafikleri

Şekil 4 göstermektedir ki 1712 AGİ'den 1717 AGİ ile 1721 AGİ'ye taşınan verilerin Yanlılık Düzeltmesi sonucunda elde edilen değerlerin birbirlerine oldukça yakın olduğu görülmektedir. $\phi$ üstel ve $\mathrm{K}$ düzeltme katsayılarının Yanlılık Düzeltmesi sonucu ortalama değerlerin kullanılması sapmaları önemli ölçüde azaltmıştır [2]. 1712-1717 arası ile 1712-1721 arası mesafeler yakın olup düzeltme sonucu elde edilen değerler açısından bağıl hata yüzdeleri düşünüldüğünde 1712 AGİ'den 1721 AGI'ye taşınan verilerin yaklaşık 1.64 hata oranında gerçek değerlere daha yakın sonuçlar ortaya koyduğu gözlemlenmiştir (Şekil 5) [2, 4].

\section{Sonuç}

Bu çalışmada, Türkiye'nin önemli su potansiyeline sahip havzalarından biri olan Doğu Akdeniz Havzası'ndaki Elektrik İşleri Etüt İdaresi (EİEİ) tarafından işletilmiş olan 1712, 1717 ve 1721 nolu Akım Gözlem İstasyonlarının (AGI) gözlemlenmiş akım verileri kullanılarak 1987-2011 yılları arası 25 yıllık ortalama aylık akım verileri değerlendirilmiştir. 1712 nolu istasyonun verileri, birbirlerinden farklı mesafedeki 1717 ve 1721 nolu istasyonların bulunduğu konuma Drenaj Alan- Oran 
(DAR) metodu ile taşınmıştır. Elde edilen değerler orijinal veriler ile karşılaştırılarak yöntemin doğruluğu kontrol edilmiştir.

(a) 1712-1717 Ham ve Düzeltilmiş Veri-Debi Süreklilik Ĕgrisi

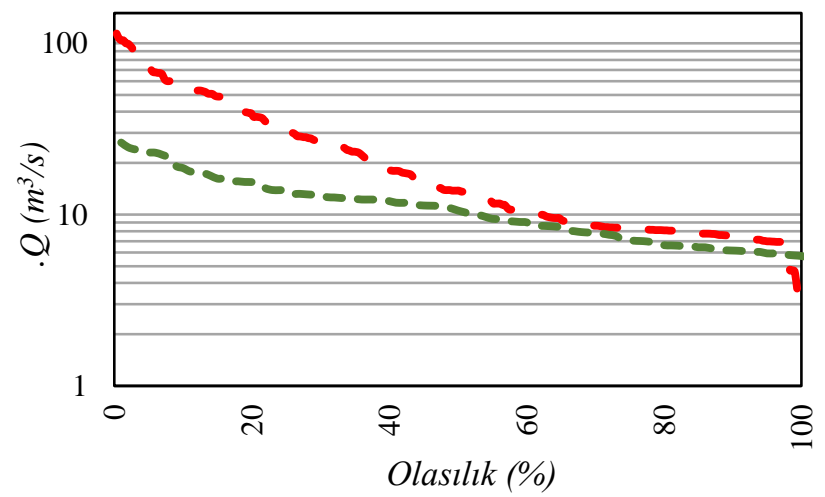

- - 1717 AGI Ham Veri —- Taşınan- Düzeltilmiş Veri

(b) 1712-1721 Ham ve Düzeltilmiş Veri-Debi Süreklilik Ĕ̆risi

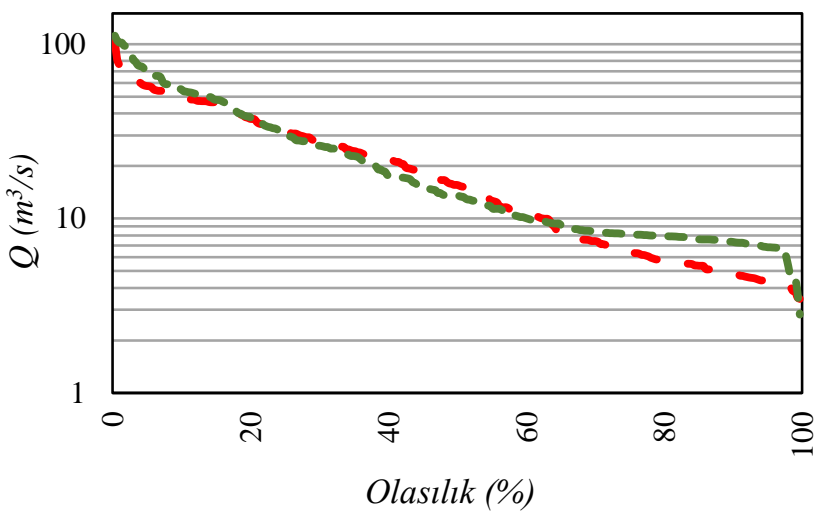

- 1721 AGİ Ham Veri - - Taşınan- Düzeltilmiş Veri

Şekil 5. (a) 1712 AGI'den 1717 AGI'ye taşınan ve düzeltilmiş veri debi süreklilik eğrisi, (b) 1712'den 1721 AGI'ye taşınan ve düzeltilmiş veri debi süreklilik ĕgrisi

Yanlılık Düzeltmesi (Bias Correction) uygulandığında taşınan verilerin gözlenen veriler ile ne oranda yakınsak olduğu üzerine incelemeler yapılmıştır. Çalışma sonucunda düzeltmelerle birlikte elde edilen değerlerin gözlenmiş verilere daha yakın olduğu görülmektedir. $\mathrm{Bu}$ durumun nedeninin metotta kullanılan $\phi$ üstel ve K düzeltme katsayılarının sabit bir değer değil de ortalamalar üzerinde hesaplanması olarak belirtilebilir. İlerleyen zamanlarda drenaj havzalarının meteorolojik ve hidrolojik koşullarının da göz önüne alındığı farklı çalışmalarla akımların taşınmasında istasyonlar arasında mesafenin doğruluğu nasıl etkileyebileceği konusunda çalışmalar düşünülebilir. $\mathrm{Su}$ kaynaklarının doğru ve etkili yönetimi süreçleri ele alındığında doğruya yakın düzeltmelerle su yapılarının tasarım ve planlamalarına pozitif anlamda etkiler sağlayabileceği öngörülebilmektedir.

\section{Teșekkür}

$\mathrm{Bu}$ çalışmayı hazırlarken, değerli yardımları için Adana Alparslan Türkeş Bilim ve Teknoloji Üniversitesi Mühendislik Fakültesi İnşaat Mühendisliği Bölümü öğrencilerinden Kutbettin ÖZCAN'a çok teşekkür ederiz.

\section{Kaynakça}

[1] R. Bakış, ve S. Göncü, "Akarsu debi ölçümlerinde eksik verilerin tamamlanması: Zap Suyu Havzası Örneği”" Anadolu Üniversitesi Bilim ve Teknoloji Dergisi AUygulamalı Bilimler ve Mühendislik, vol. 16(1), pp. 63-79, 2015. doi: 10.18038/btd-a.45640

[2] R. Bakış, F. Ç. Şirin, ve Y. Bayazıt, “Akım gözlem istasyonları için Alan- Oran metodunun doğruluğunun analizi" İklim Değişikliği ve Çevre, vol. 5(2), pp. 8-15, 2020.

[3] K. Saplığlu, T. S. K. Öztürk, ve F. A. Şenel, "Eksik hidrolojik verilerin simbiyotik organizmalar arama algoritması ile tahmini" Çanakkale Onsekiz Mart Üniversitesi Fen Bilimleri Enstitüsü Dergisi, vol. 6(1), pp. 93-104, 2020.

[4] USGS Bureau of Reclamation, Evaluation of DrainageArea Ratio Method Used to Estimate Streamflow for the Red River of the North Basin, North Dakota and Minnesota, 2005.

[5] K. Ergen, ve E. Kentel, "An integrated map correlation method and multiple-source sites drainage-area ratio method for estimating streamflows at ungauged catchments: A case study of the Western Black Sea Region, Turkey" Journal of Environmental Management, vol. 166, pp. 309-320, 2016.

[6] M. U. Y1lmaz, ve B. Önöz, "Evaluation of statistical methods for estimating missing daily streamflow data" Teknik Dergi, vol. 30(6), pp. 9597-9620, 2019. https://doi.org/10.18400/tekderg.421091

[7] M. U. Yılmaz, ve B. Önöz, "A comparative study of statistical methods for daily streamflow estimation at ungauged basins in Turkey" Water MDPI, vol. 12(2), 459, pp. 1-22, 2020. https://doi.org/10.3390/w12020459

[8] F. Saka, ve H. T. Babacan, "Discharge estimation by drainage area-ratio method at some specific discharges for 2251 stream gauging station in East Black Sea Basin, Turkey" Journal of Investigations on Engineering \& Technology, vol. 2(1), pp. 22-25, 2019.

[9] Su Yönetimi Genel Müdürlüğü (SYGM), Doğu Akdeniz Havzası Kuraklık Yönetim Planı, T.C. Orman ve Su İşleri Bakanlığg, Ankara, Türkiye, 2018.

[10] Elektrik İşleri Etüt İdaresi (EİEİ), Akım Gözlem Yıllıkları, Enerji ve Tabii Kaynaklar Bakanlığı, Ankara, Türkiye, 2011.

[11] Devlet $\mathrm{Su}$ İşleri Genel Müdürlüğü (DSI), Resmi Su Kaynaklarl Istatistikleri, T.C. Orman ve $\mathrm{Su}$ İşleri Bakanlığı, Ankara, 2019. 